Article

\title{
Interaction Mechanism of Thermal and Mechanical Field in KDP Fly-Cutting Process
}

\author{
Chenhui An ${ }^{1, *(1)}$, Ke Feng ${ }^{2}$, Wei Wang ${ }^{2}$, Qiao Xu ${ }^{1}$, Xiangyang Lei ${ }^{1}$, Jianfeng Zhang ${ }^{1}$, Xuelian Yao ${ }^{1}$ \\ and Haibo $\mathrm{Li}^{1}$ \\ 1 Laser Fusion Research Center, CAEP, Mianyang 621900, China; xuqiao@vip.sina.com (Q.X.); \\ leixiangyang2@163.com (X.L.); xxxxxx5726@vip.sina.com (J.Z.); xlyao93@163.com (X.Y.); \\ haiya126@sina.com (H.L.) \\ 2 School of Mechanical and Electrical Engineering, University of Electronic Science and Technology, \\ Chengdu 611731, China; duying0108@163.com (K.F.); wangwhit@163.com (W.W.) \\ * Correspondence: hplaser@126.com
}

Citation: An, C.; Feng, K.; Wang, W.; Xu, Q.; Lei, X.; Zhang, J.; Yao, X.; Li,

$H$. Interaction Mechanism of Thermal and Mechanical Field in KDP Fly-Cutting Process. Micromachines 2021, 12, 855. https://doi.org/ $10.3390 / \mathrm{mi1} 2080855$

Academic Editors: Benny C.

F. Cheung and Jiang Guo

Received: 22 June 2021

Accepted: 16 July 2021

Published: 21 July 2021

Publisher's Note: MDPI stays neutral with regard to jurisdictional claims in published maps and institutional affiliations.

Copyright: (c) 2021 by the authors. Licensee MDPI, Basel, Switzerland. This article is an open access article distributed under the terms and conditions of the Creative Commons Attribution (CC BY) license (https:// creativecommons.org/licenses/by/ $4.0 /)$.

\begin{abstract}
As an important nonlinear optical material, potassium dihydrogen phosphate (KDP) crystal is used in high-power laser beams as the core element of inertial confinement fusion. It is the most general method of single point diamond fly-cutting (SPDF) to produce high precision and crack-free KDP surfaces. Nevertheless, the cutting mechanism of such material remains unclear, and therefore needs further analysis. Firstly, the stress field, cutting force and cutting temperature under different working conditions are calculated by a KDP crystal cutting simulation model. Then, the rules and the cause of change and interaction mechanisms of force and temperature are analyzed by comparing the measurement experiments with simulations. Furthermore, the causes of chip formation and micro-cracks on the machined surface are analyzed based on thermo-mechanical coupling and chip morphology. The conclusion can be deduced: Although the temperature has not reached the phase transition temperature during the finishing process, under high cutting speeds and large unformed chip thickness, such as semi-finishing and roughing, the temperature can reach up to $180^{\circ} \mathrm{C}$ or higher, and KDP crystals are very likely to phase transition—chip morphology also verifies this phenomenon.
\end{abstract}

Keywords: potassium dihydrogen phosphate (KDP) crystal; single point diamond fly-cutting; interaction mechanism; chip morphology; phase transition temperature

\section{Introduction}

Potassium dihydrogen phosphate $\left(\mathrm{KH}_{2} \mathrm{PO}_{4}, \mathrm{KDP}\right)$ is a unique artificial crystal that can grow to a diameter greater than $500 \mathrm{~mm}$, and it has excellent nonlinear optical properties [1]; therefore, it is the only nonlinear optical element material that can be used in high-energy laser beams [2]. However, due to its disadvantageous properties such as deliquescence, fragmenting and strong anisotropy, it is less possible to process the KDP crystal by grinding, polishing and other traditional methods $[3,4]$. Hence, single point diamond fly-cutting is the most feasible process method for KDP crystal, and because of the high requirement of the crystal elements such as nanoscale roughness and micron level surface accuracy, the ultra-precision fly-cutting machine tools are adapted and the fine finishing process is analyzed [5]. A single point diamond fly-cutting machine with a large diameter cutting head, which can effectively avoid the mentioned disadvantages and reduce the effect of the material anisotropy influence, is the most common machining method for large caliber KDP crystal components [6].

In the KDP crystal fly-cutting process, the cutting speed could reach up to $10 \mathrm{~m} / \mathrm{s}$, which is higher than that in ordinary turning processes. Under such a high cutting speed, on one hand, the crystal material near the cutting zone will incur a large plastic deformation, and on the other hand, it causes severe friction between cutting tools and workpieces. The plastic deformation and severe friction would produce heat, which would increase the 
material's temperature near the cutting zone $[7,8]$, resulting in some surface defects such as phase transition, recrystallization and micro-cracks, especially for the KDP crystal of which the phase transition temperature is only $182.3^{\circ} \mathrm{C}$ [9].

Lo [10] established a finite element model to represent the cutting process by using diamond tools with different rake angles, taking the influence of the edge radius into account. Zong [11,12] established a finite element model to simulate the entire diamond turning process, and found an optimal selection of tool geometries for the KDP cutting process, i.e., $-25^{\circ}$ rake angle and $8^{\circ}$ clearance angle [13]. A new constitutive model was used by Wang [14] to simulate the cutting process of KDP crystal, which combines the anisotropic elastic and pressure-dependent plastic model and is performed to investigate the influence of cutting parameters on the brittle ductile transition depth and cutting force. In [15], the authors took research on the thermal field of DKDP crystal cutting and explored the influence of process parameters on the cutting temperature. However, there are few studies on the thermo-mechanical coupling phenomenon in the KDP crystal cutting process.

At the same time, there are many scholars involved in the research on material properties. Zhang [16] tested the mechanical parameters of KDP crystals and found that brittle failure is easier to appear in [100] crystal orientation than [001] crystal orientation, and the compressive strength is much higher than tensile strength. In 2015, Ding [9] studied the high temperature thermal behavior and thermal dehydration reaction of KDP crystal, and the main conclusion is that the KDP crystal is still tetragonal and has no phase transition of the monoclinic phase at $183^{\circ} \mathrm{C}$, and then the dehydration reaction begins to decompose at $207^{\circ} \mathrm{C}$. Hou [17] used XRD (X-ray diffraction) to analyze the residual stress of the subsurface of KDP crystal. It is found that the residual stress in the vertical [112] plane is higher than other planes at different cutting depths, and its value is about $30 \mathrm{MPa}$, which is about 7 times that of the parallel [112] plane residual stress. In 2018, Huang [18] studied the KDP crystal cracking caused by temperature inhomogeneity, and found that when the crystal has an internal temperature difference of $4{ }^{\circ} \mathrm{C}$ in a small spatial scale of about tens of millimeters, the maximum residual heat stress would be very close to or even exceed the tensile strength of $6.67 \mathrm{MPa}$ [19], which made the crystals easier to crack.

There are many kinds of methods that can be used to measure the online temperature in the machining process, and the most common method is using embedded thermocouple probes [16]. Thus, this kind of probe must be embedded in the measured position, and they need a high coefficient of heat conduction of the measured objects, both of which cannot be fulfilled in the KDP cutting process [20,21]. In the KDP crystal fly-cutting process, the linear velocity of the diamond tool is above $10 \mathrm{~m} / \mathrm{s}$, and measuring the temperature distribution in the KDP cutting process is extremely difficult due to the small shear area and low heat production [21]. Therefore, a kind of high-speed infrared camera is necessary in this situation which can meet both requirements of remote measurement and high temporal resolution. The ImageIR ${ }^{\circledR} 5300$ has a sampling frequency as high as $12 \mathrm{kHz}$, and its maximum resolution is $0.02{ }^{\circ} \mathrm{C}$, which is the ideal equipment for this experiment.

In short, although lots of research works are published about the cutting force and the temperature change in the KDP crystal fly-cutting process, few studies have combined the temperature and stress analysis together, although both of which would have effects on the material removal mechanism. This paper is based on the anisotropic finite element model of KDP crystal to study the interaction of the thermal and mechanical field in KDP crystal cutting and its influence on chip morphology. It is the main method by combining simulations on the stress field, temperature field and cutting force with experimental verification results. Studying the interaction of the thermal and mechanical field is helpful to understand the material removal mechanism, verify the material changes in the cutting process, and reveal the phase transformation and surface defects that may be caused by the heating produced in the fly-cutting process. 


\section{Simulation}

\subsection{Simulation Modeling}

As is shown in Figure 1a, in the KDP fly-cutting process, the workpiece is placed horizontally and fed at a constant velocity, while the spindle with the diamond cutting tool rotates at a given speed. Along the main cutting direction, the section of the removed workpiece material produced by the arc edge tool is circular, which can be regarded as the superposition of many sections with different cutting depths, so the three-dimensional problem can be transformed into a series of two-dimensional plane problems with certain thicknesses. In Figure $1 \mathrm{~b}$, the area enclosed by the three points of $\mathrm{O}^{\prime} \mathrm{A}^{\prime} \mathrm{B}^{\prime}$ is an undeformed chip.

$$
t_{c}=R-\sqrt{R^{2}+f^{2}-2 f \sqrt{2 R a_{p}-a_{p}^{2}}}
$$

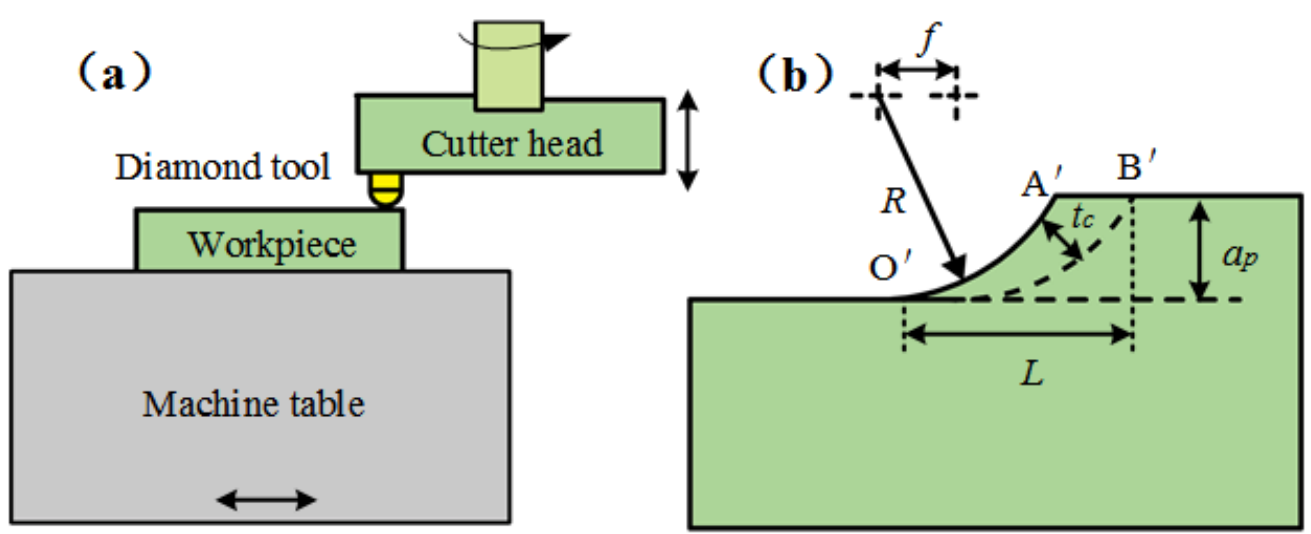

Figure 1. (a) Fly-cutting schematic diagram; (b) Undeformed chip thickness.

The max value of the unformed chip thickness $t_{c}$ can be calculated according to Equation (1), where $R$ is the nose radius and the value is $5 \mathrm{~mm}, f$ is feed and the value is $10 \mu \mathrm{m} / \mathrm{rev}$ according to the actual situation, and $a_{p}$ is the cutting depth.

Figure 2 shows the finite element simulation model of KDP crystal. The KDP crystal workpiece is rectangular with a size of $100 \mu \mathrm{m} \times 30 \mu \mathrm{m}$. The 3600 four-node plane strain units (CPE4) are used to complete the mesh. The bottom of the KDP crystal is completely fixed in a horizontal manner. Compared with the soft KDP crystal, the diamond tool is far harder and is often regarded as a rigid body and moves to the left of the workpiece at a certain speed. The parameters of the diamond tool are as follows: the edge radius is $120 \mathrm{~nm}$, the tool clearance angle is $18^{\circ}$, and the tool rake angle is $-45^{\circ}$. The 300 four-node plane strain units are used to mesh the diamond tool.

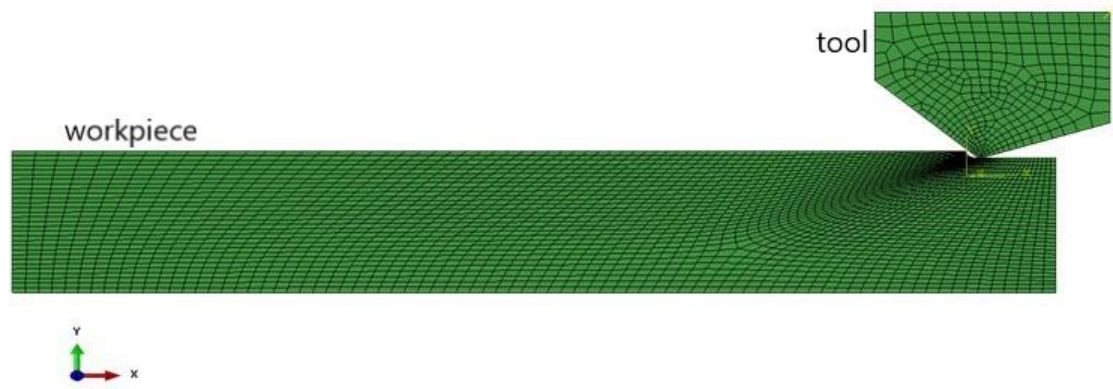

Figure 2. KDP crystal cutting process finite element simulation model. 


\subsection{Material Properties}

\subsubsection{Diamond}

The KDP crystal fly-cutting process mainly involves two different materials. The processed material is KDP crystal, which is characterized by low hardness and high brittleness, and the tool material is natural diamond, which is the hardest material in the world. The hardness of diamond is more than 10 times that of KDP crystal. The specific material properties of natural diamond are shown in Table 1.

Table 1. Natural diamond material properties.

\begin{tabular}{cc}
\hline Physical Quantity & Value \\
\hline Elastic modulus $(\mathrm{Gpa}))$ & 1114 \\
Poisson ratio & 0.07 \\
Linear expansion coefficient $\left(\mu \mathrm{m} /\left(\mathrm{m} \cdot{ }^{\circ} \mathrm{C}\right)\right)$ & 1.18 \\
Specific heat capacity $\left(\mathrm{J} /\left(\mathrm{Kg}{ }^{\circ} \mathrm{C}\right)\right)$ & 507.9 \\
Thermal conductivity $\left(\mathrm{W} /\left(\mathrm{m}^{\circ} \mathrm{C}\right)\right)$ & 2000 \\
Density $\left(\mathrm{kg} / \mathrm{m}^{3}\right)$ & 3520 \\
\hline
\end{tabular}

\subsubsection{KDP Crystal}

Since the KDP crystal is an anisotropic material, the structure of the KDP crystal is a tetragonal system, and the matrix of the elastic phase is composed of six mutually independent parameters to characterize the stress-strain relationship of the KDP crystal. The stress-strain relationship inside the KDP crystal material can be expressed by the stiffness matrix of the material, as shown in Equation (2):

$$
\left[\begin{array}{c}
\sigma_{x} \\
\sigma_{y} \\
\sigma_{z} \\
\tau_{x y} \\
0 \\
0
\end{array}\right]=\left[\begin{array}{llllll}
C_{11} & C_{12} & C_{12} & & & \\
C_{12} & C_{11} & C_{13} & & & \\
C_{13} & C_{13} & C_{33} & & & \\
& & & C_{44} & & \\
& & & & C_{66} & \\
& & & & & C_{66}
\end{array}\right]\left[\begin{array}{c}
\varepsilon_{x} \\
\varepsilon_{y} \\
0 \\
\gamma_{x y} \\
0 \\
0
\end{array}\right]
$$

There, $\varepsilon_{x}, \varepsilon_{y}$, and $\gamma_{x y}$ are the strain components, and $C_{11} \sim C_{66}$ are the elastic constants of KDP crystal.

Table 2 shows the KDP crystal stiffness coefficient values, which can express the properties inside the KDP crystal.

Table 2. Stiffness constant value [22].

\begin{tabular}{cccccc}
\hline$C_{11}$ & $C_{12}$ & $C_{13}$ & $C_{33}$ & $C_{44}$ & $C_{66}$ \\
\hline $71.6 \mathrm{GPa}$ & $-6.3 \mathrm{GPa}$ & $14.9 \mathrm{GPa}$ & $56.4 \mathrm{GPa}$ & $12.5 \mathrm{GPa}$ & $6.2 \mathrm{GPa}$ \\
\hline
\end{tabular}

When the KDP material is in the plastic stage, the final model of the material constitutive equation can be derived from Equation (3):

$$
\left\{\begin{array}{c}
\sigma=471.227 \varepsilon^{0.1721}(\sigma \geq 181.725 \mathrm{MPa}) \\
\sigma_{\text {ture }}=\sigma(1+\varepsilon) \\
\varepsilon_{p}=\ln (1+\varepsilon)-\sigma_{\text {ture }} / E
\end{array}\right.
$$

where $\sigma_{\text {ture }}$ is the true rheological stress and $\varepsilon_{p}$ is plastic deformation [10].

Temperature is accompanied by the cutting process, so temperature analysis is an integral part of the finite element simulation of KDP crystal fly-cutting. The heat transfer in the shear zone would change the plastic deformation; therefore, the surface micro structure may be changed. The diamond tool is a rigid body relative to the KDP crystal and only heat transfer is calculated, and the KDP crystal workpiece is a deformable body, and the thermal 
and mechanical effects are analyzed in the simulation. In the heat transfer analysis of the KDP crystal, the heat conduction and convection calculations are performed. Relative thermal parameters of diamond tools and Type II KDP crystals, for example, the specific heat capacity $C$, thermal conductivity $\alpha$, thermal expansion coefficient $\lambda$ and thermal emissivity $k$, are listed in Table 3.

Table 3. Thermal parameters of diamond tools and type II KDP crystals.

\begin{tabular}{|c|c|c|c|c|}
\hline Parameters & Diamond & \multicolumn{3}{|c|}{ KDP Crystal } \\
\hline \multirow{2}{*}{$\alpha\left[\mu m /\left(m^{\circ} \mathrm{C}\right)\right]$} & \multirow{2}{*}{2000} & $\alpha_{x}$ & $\alpha_{y}$ & $\alpha_{z}$ \\
\hline & & 16.1 & 16.1 & 29.0 \\
\hline \multirow{2}{*}{$\lambda\left(10^{-6} /{ }^{p} \mathrm{C}\right)$} & \multirow{2}{*}{1.18} & $\lambda_{x}$ & $\lambda_{y}$ & $\lambda_{z}$ \\
\hline & & 2.0 & 2.0 & 3.0 \\
\hline $\mathrm{C}\left[J /\left(\mathrm{kg}^{\circ} \mathrm{C}\right)\right]$ & 502 & \multicolumn{3}{|c|}{$\begin{aligned}-120+4.56 \mathrm{~T}-7.38\left(10^{-3}\right) \mathrm{T}^{2}+6.59\left(10^{-6}\right) \mathrm{T}^{3}-3.05\left(10^{-9}\right) \mathrm{T}^{4}+5.72\left(10^{-13}\right) \mathrm{T}^{5} \\
(273 \mathrm{~K}<\mathrm{T}<1500 \mathrm{~K})\end{aligned}$} \\
\hline$k$ & 0.03 & \multicolumn{3}{|c|}{0.36} \\
\hline
\end{tabular}

Figure 3 shows the temperature in different directions - the cutting depth is $2 \mu \mathrm{m}$ (the max value of the unformed chip thickness is $297 \mathrm{~nm}$ ) and the line velocity of the diamond tool is $10 \mathrm{~m} / \mathrm{s}$. (a) The cutting direction is [100] crystal orientation, and the temperature is $90{ }^{\circ} \mathrm{C}$. (b) The cutting direction is [001] crystal orientation, and the temperature is $96{ }^{\circ} \mathrm{C}$, indicating that the anisotropy has a certain influence on the cutting temperature of the KDP crystal, and it is better to cut along [100] crystal orientation as a lower hit is being produced in this direction.

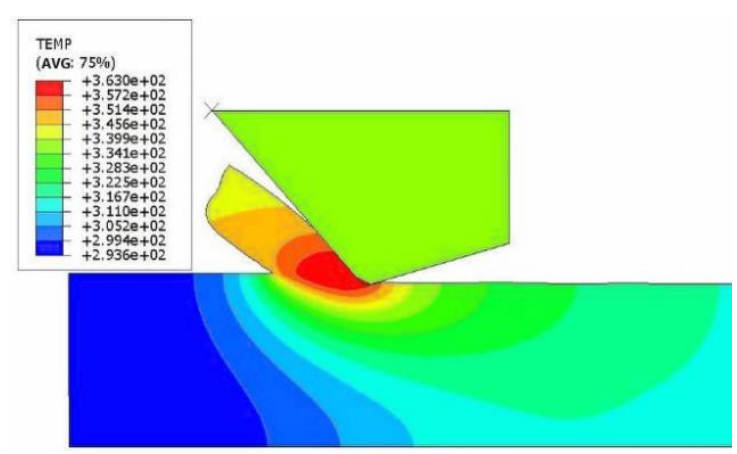

(a)

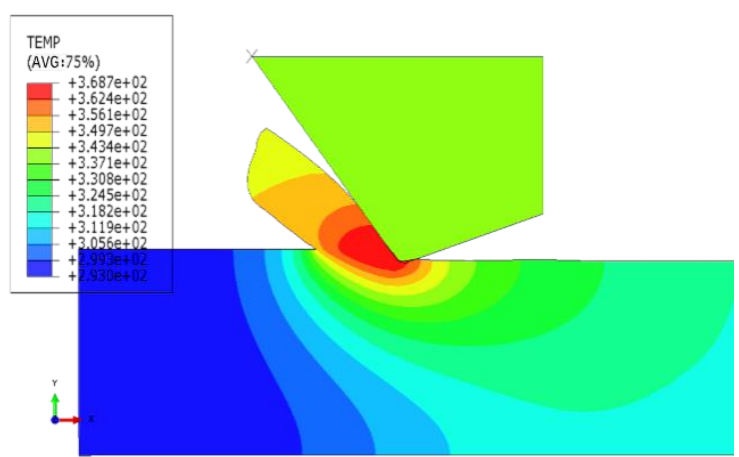

(b)

Figure 3. Temperature distribution along different crystal orientations: (a) [100] crystal orientation, (b) [001] crystal orientation.

\section{Experiment}

\subsection{Cutting Experiment}

As shown in Figure 4, in order to measure the force and temperature in the process of KDP crystal, a vertical ultra-precision turning machine tool was used-the spindle rotation error is $0.1 \mu \mathrm{m}$, the feed repetition accuracy is $0.1 \mu \mathrm{m}$, and the spindle speed can reach $8000 \mathrm{r} / \mathrm{min}$. 


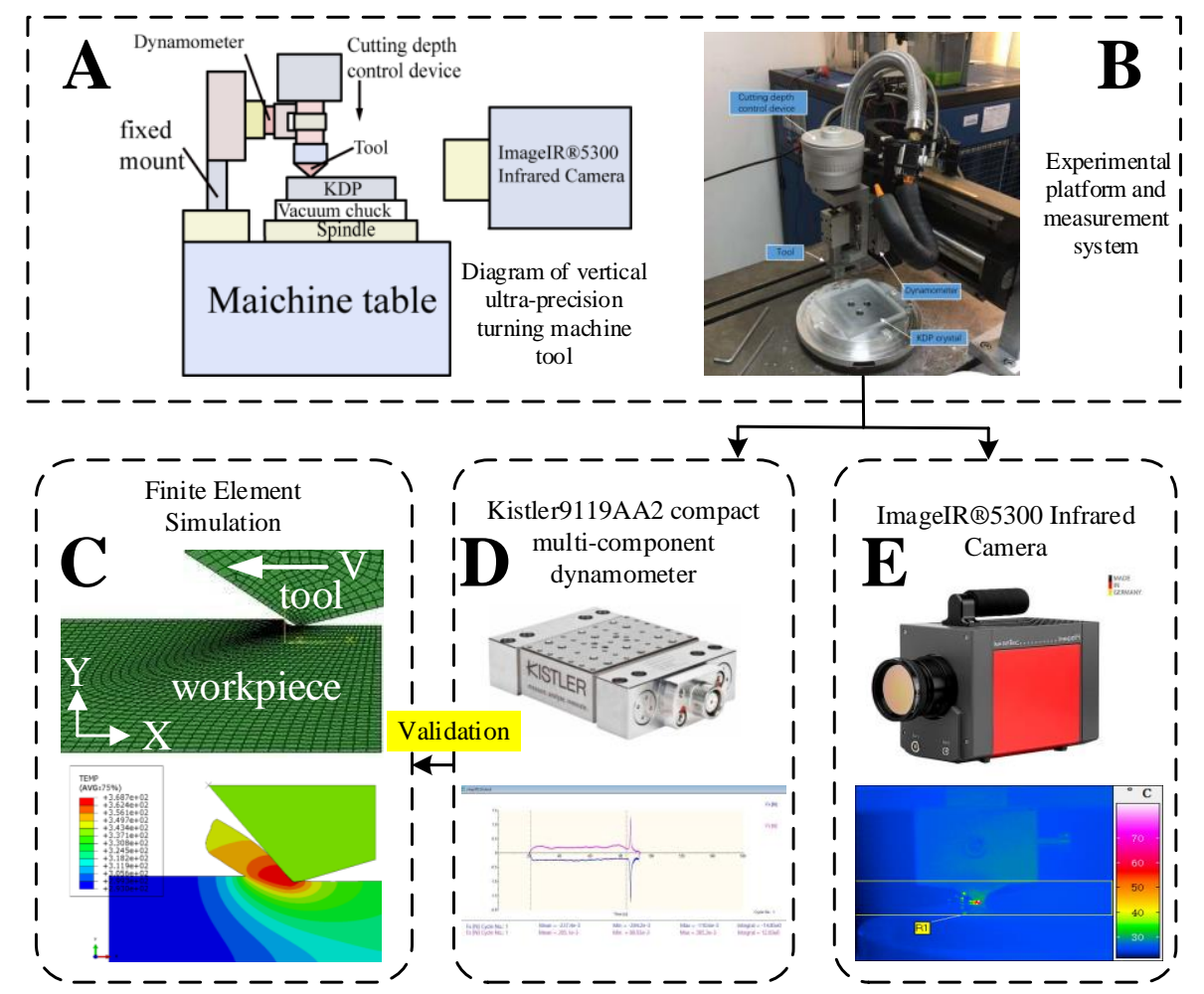

Figure 4. Experimental platform and measurement system: (A) Diagram of vertical ultra-precision turning machine tool; (B) Experimental platform and measurement system; (C) Finite Element Simulation; (D) Kistler9119AA2 compact multi-component dynamometer; (E) ImageIR ${ }^{\circledR} 5300$ Infrared Camera.

The tool selected for the ultra-precision cutting machine tool was a diamond arc-edge tool. The parameters of the tool are consistent with those in the simulation model, as shown in Table 4.

Table 4. Diamond tool parameters.

\begin{tabular}{cccc}
\hline Rake Angle & Flank Angle & Nose Radius & Edge Radius \\
\hline$-45^{\circ}$ & $18^{\circ}$ & $5 \mathrm{~mm}$ & $120 \mathrm{~nm}$ \\
\hline
\end{tabular}

The unformed chip thickness and cutting speed both need to be analyzed in order to obtain the effect of single process parameters on KDP crystal fly-cutting, and orthogonal experiments of cutting speed and unformed chip thickness are used to complete the influence of single parameters on the cutting force and cutting temperature. The experimental parameters were designed as shown in Table 5.

Table 5. Experimental design parameters.

\begin{tabular}{|c|c|}
\hline Parameters & Value \\
\hline $\begin{array}{c}\text { cutting speed } \\
\text { feed }\end{array}$ & $\begin{array}{c}3 \mathrm{~m} / \mathrm{s}, 5 \mathrm{~m} / \mathrm{s}, 8 \mathrm{~m} / \mathrm{s}, 10 \mathrm{~m} / \mathrm{s}, 15 \mathrm{~m} / \mathrm{s} \\
10 \mu \mathrm{m} / \mathrm{rev}\end{array}$ \\
\hline $\begin{array}{l}\text { the max value of the unformed chip thickness } \\
\text { (cutting depth) }\end{array}$ & $297 \mathrm{~nm}(2 \mu \mathrm{m}), 429 \mathrm{~nm}(5 \mu \mathrm{m}), 622 \mathrm{~nm}(10 \mu \mathrm{m})$ \\
\hline
\end{tabular}

In the KDP crystal fly-cutting process, the process parameters are small, such as the $\mu \mathrm{m}$ range cutting depth, and the cutting forces are always less than $0.1 \mathrm{~N}$; therefore, a high accuracy measurement device for the cutting force is required. Figure 4D shows the Kistler9119AA2 compact multi-component dynamometer used in this experiment. The 
dynamometer is compact in design, has high sensitivity and natural frequency, and has small temperature error. It is very suitable for measuring the change in cutting force in ultra-precision machining processes.

In the KDP crystal fly-cutting process, the diamond tool rotates with the spindle at a high speed, the line velocity of the cutter can exceed $10 \mathrm{~m} / \mathrm{s}$, and the contact period between the tool and KDP crystal is very short, so it is necessary to use a temperature measurement system with a high frequency response. The $\mathrm{IR}^{\circledR} 5300$ infrared camera used in this experiment is shown in Figure 4E. Its sampling frequency is as high as $12 \mathrm{kHz}$, its maximum resolution is $0.02{ }^{\circ} \mathrm{C}$, and it can measure the weak temperature changes in high-speed cutting areas.

\subsection{KDP Chip Morphology Observation Experiment}

Studying the chip morphology formed by high-speed cutting is helpful to explain the chip formation mechanism. The chip forming process is the plastic deformation of the workpiece material sliding along the shear surface after being pushed by the tool rake face. Chip shape can explain the deformation mechanism and process in the cutting process, and indirectly explain the quality of the workpiece surface. Based on the observation of chip morphology, the influence of process parameters and temperature on chip formation can be analyzed by combining the simulation and experimental results.

In this experiment, the NeoScope Jcm-5000 desktop scanning electron microscope was used to observe the KDP chip morphology. The surface morphology of the chips after finishing, semi-finishing and roughing was observed, respectively, and the process parameters are consistent with those in the simulation and measurement experiments.

\section{Results}

\subsection{Results Comparison of Cutting Force}

Figure 5 shows the cutting force measurement chart at the cutting speed of $3 \mathrm{~m} / \mathrm{s}$ and the unformed chip thickness of $429 \mathrm{~nm}$. $F_{x}$ is the horizontal cutting force and $F_{z}$ is the vertical cutting force. The data between the two dotted lines in the figure are the cutting force measurement results from the cutting tool to the workpiece in the cutting process. From the figure, we can calculate the average values of the horizontal and vertical cutting forces, which are $0.237 \mathrm{~N}$ and $0.205 \mathrm{~N}$, respectively.

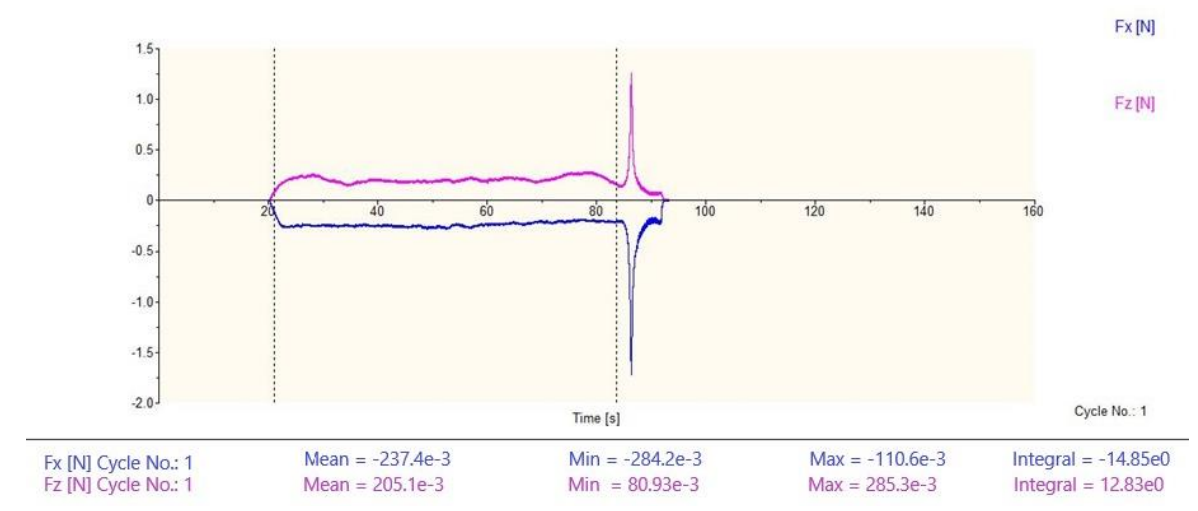

Figure 5. Cutting force measurement chart.

Figure 6a shows the comparison of cutting forces at different cutting speeds under the max unformed chip thickness of $429 \mathrm{~nm}$. In the figure, it can be found that: (1) cutting speed ranged from $3 \mathrm{~m} / \mathrm{s}$ to $10 \mathrm{~m} / \mathrm{s}$, both $\mathrm{F}_{\mathrm{Z}}$ and $\mathrm{F}_{\mathrm{x}}$ decreased by $20-30 \%$ with the increase in cutting speed, meanwhile the simulation results and experimental results have the same trend and the numerical values are close, which shows that the simulation is in line with the actual situation. (2) When the cutting speed increased from $10 \mathrm{~m} / \mathrm{s}$ to $15 \mathrm{~m} / \mathrm{s}$, the variation trends of the measured and simulated cutting force were different. The simulated cutting force $\mathrm{F}-\mathrm{S}_{\mathrm{im}}$ decreased with the increase in the cutting speed, but the experimental 
cutting force $F-E_{x p}$ increased. The main reason is that the chip generation rate is higher than the chip discharge rate, and the cutting force is affected by the chip accumulation in the actual process; in addition, with the increase in machine speed, the stability of the machine tool will become worse, which affects the measurement of cutting force.
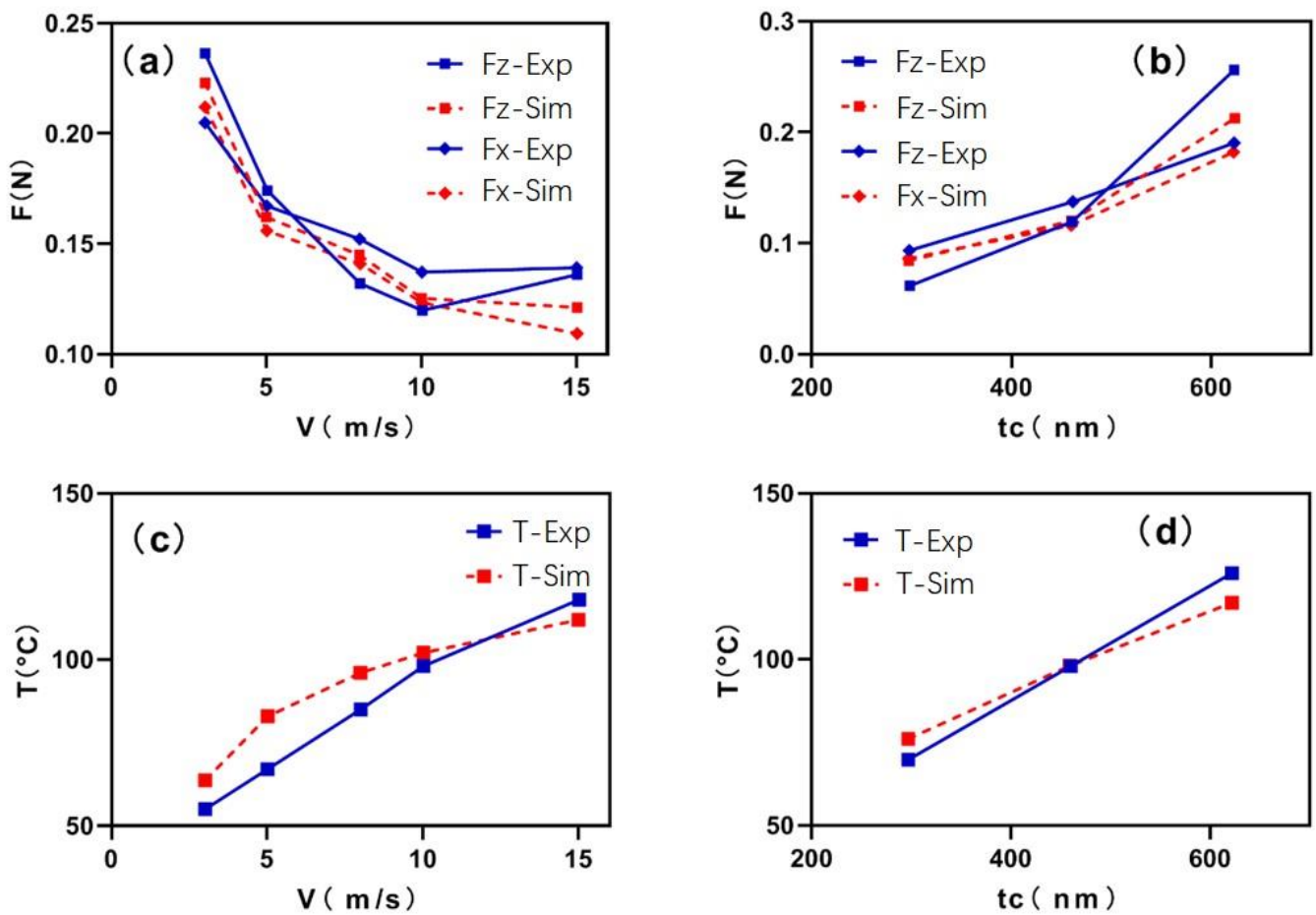

Figure 6. Variation of cutting force and temperature under different cutting conditions. (a) Comparison of cutting forces at different cutting speeds under the same unformed chip thickness of $429 \mathrm{~nm}$. (b) The comparison of cutting forces at different unformed chip thicknesses under the cutting speed of $10 \mathrm{~m} / \mathrm{s}$. (c) Comparison of cutting temperatures at different cutting speeds and unformed chip thickness of $429 \mathrm{~nm}$. (d) Comparison of cutting temperature at different cutting and depth cutting speed of $10 \mathrm{~m} / \mathrm{s}$.

Figure $6 \mathrm{~b}$ shows the comparison of cutting forces at different unformed chip thicknesses under the cutting speed of $10 \mathrm{~m} / \mathrm{s}$. In the figure, $F_{z}$ and $F_{x}$ increased with the increase in depth. When the cutting speed remains constant, the measured and simulated values of cutting force at different cutting depths are basically the same trend, and the numerical values are close, which shows that the finite element simulation model is in line with the actual situation and therefore can be convinced.

\subsection{Results Comparison of Cutting Temperature}

Figure $7 \mathrm{a}, \mathrm{b}$ show the cutting temperature images of KDP crystal taken by the ImageIR ${ }^{\circledR} 300$ infrared thermal camera. When the cutting speeds are $5 \mathrm{~m} / \mathrm{s}$ and $10 \mathrm{~m} / \mathrm{s}$, respectively, the unformed chip thickness remains $429 \mathrm{~nm}$. The maximum values of the measured temperatures are $70{ }^{\circ} \mathrm{C}$ and $98^{\circ} \mathrm{C}$, respectively. 


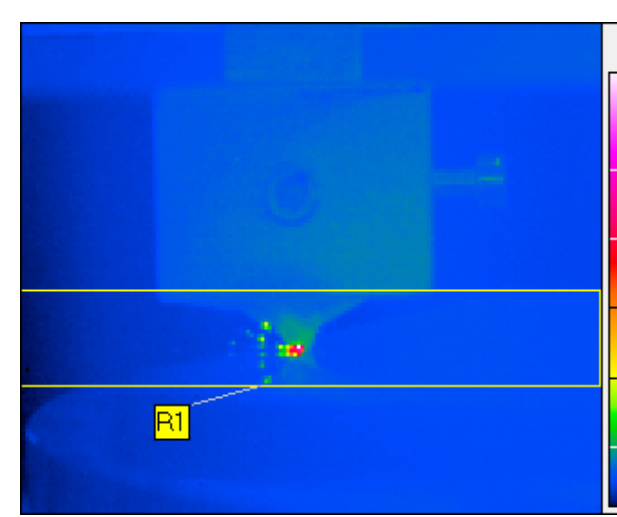

(a)
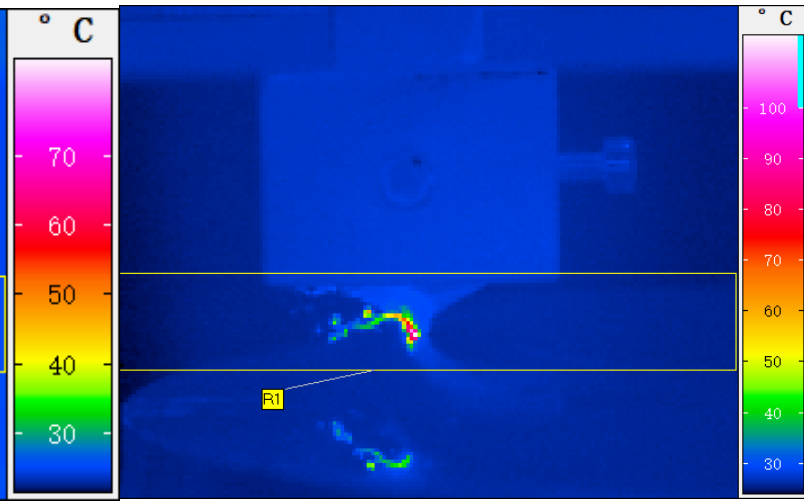

(b)

Figure 7. Cutting temperature images: (a) Cutting speed $5 \mathrm{~m} / \mathrm{s}$, (b) Cutting speed $10 \mathrm{~m} / \mathrm{s}$.

Figure $6 c$ shows the comparison of cutting temperature results at different cutting speeds under the unformed chip thickness of $429 \mathrm{~nm}$. As shown in the figure, firstly, as cutting speed increased, the cutting temperature increased by $260 \%$. However, when the cutting speed increased to a certain extent, the growth rate of cutting temperature slowed down and the influence of cutting speed weakened gradually. Secondly, the maximum difference between the simulation temperature and the experimental results is less than $10{ }^{\circ} \mathrm{C}$, which shows that the accuracy of the finite element simulation model can be accepted. Thirdly, when the unformed chip thickness was $429 \mathrm{~nm}$ and the cutting speed was $15 \mathrm{~m} / \mathrm{s}$, the simulation temperature of the chip reached $112{ }^{\circ} \mathrm{C}$ and the actual temperature reached $118^{\circ} \mathrm{C}$. Under such a high temperature and high speed deformation, the internal structure of the KDP crystal may change with the observation in Section 4.5, so high-speed cutting such as $15 \mathrm{~m} / \mathrm{s}$ should be avoided as much as possible in the actual process.

Figure $6 \mathrm{~d}$ shows the comparison of cutting temperature results at different unformed chip thicknesses under the cutting speed of $10 \mathrm{~m} / \mathrm{s}$. As shown in the figure, with the increase in unformed chip thickness, the cutting temperature increased by $74-90 \%$, and the trend of chip temperature change is basically the same. Then, the simulation temperature of chips is close to the experimental results, and the maximum difference is less than $10^{\circ} \mathrm{C}$, which also validates the accuracy of the simulation model.

\subsection{Influence of Cutting Speed}

Figure $8 \mathrm{a}-\mathrm{e}$ show the stress distribution at an unformed chip thickness of $429 \mathrm{~nm}$ (the cutting depth is $5 \mu \mathrm{m}$ ) and cutting speeds of $3 \mathrm{~m} / \mathrm{s}, 5 \mathrm{~m} / \mathrm{s}, 8 \mathrm{~m} / \mathrm{s}, 10 \mathrm{~m} / \mathrm{s}$ and $15 \mathrm{~m} / \mathrm{s}$. The compressive stress distribution is mainly found in the chip, and the maximum compressive stress occurs near the boundary between the workpiece and the chip along the shear direction, and the values are $309 \mathrm{MPa}, 254 \mathrm{MPa}, 243 \mathrm{MPa}, 240 \mathrm{MPa}$, and $232 \mathrm{MPa}$, respectively. The maximum cutting stress at $15 \mathrm{~m} / \mathrm{s}$ decreases by nearly $24 \%$ compared with that at $3 \mathrm{~m} / \mathrm{s}$. 


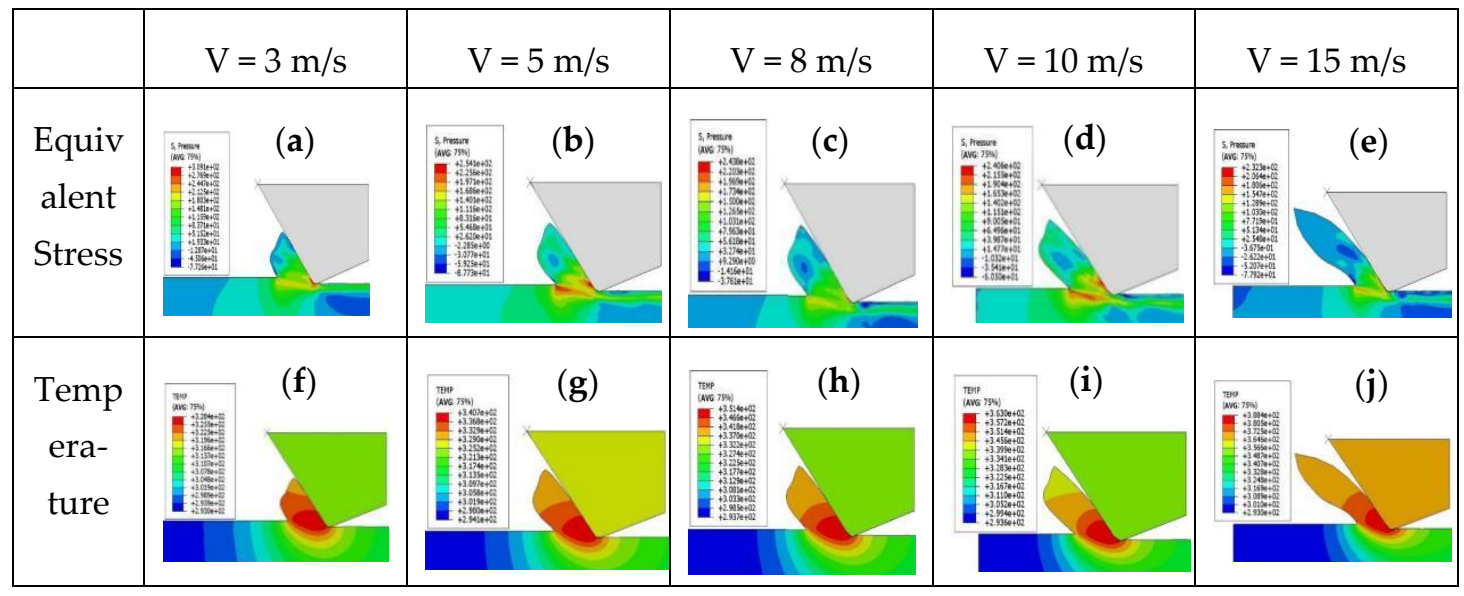

Figure 8. Stress distribution and temperature distribution of KDP crystal at different cutting speeds with unformed chip thickness of $429 \mathrm{~nm}$ : (a) Equivalent Stress of V=3 m/s; (b) Equivalent Stress of V=5 m/s; (c) Equivalent $S$ tress of V=8 m/s; (d) Equivalent Stress of V=10 m/s; (e) Equivalent Stress of V=15 m/s; (f) Temperature of V=3 m/s; (g) Temperature of V $=5 \mathrm{~m} / \mathrm{s}$; (h) Temperature of $\mathrm{V}=8 \mathrm{~m} / \mathrm{s}$; (i) Temperature of $\mathrm{V}=10 \mathrm{~m} / \mathrm{s}$; (j) Temperature of $\mathrm{V}=15 \mathrm{~m} / \mathrm{s}$.

Figure 8f,j show the temperature distribution of KDP crystals with an unformed chip thickness of $429 \mathrm{~nm}$ and different cutting speeds. The cutting speeds are $3 \mathrm{~m} / \mathrm{s}, 5 \mathrm{~m} / \mathrm{s}$, $8 \mathrm{~m} / \mathrm{s}, 10 \mathrm{~m} / \mathrm{s}$, and $15 \mathrm{~m} / \mathrm{s}$, respectively. The maximum temperatures of the chips in the figure are $55^{\circ} \mathrm{C}, 67^{\circ} \mathrm{C}, 85^{\circ} \mathrm{C}, 98^{\circ} \mathrm{C}$, and $112{ }^{\circ} \mathrm{C}$, respectively.

In Figure 8, when the unformed chip thickness was $429 \mathrm{~nm}$, as the cutting speed increased: (1) The cutting force at $15 \mathrm{~m} / \mathrm{s}$ decreased by nearly $25 \%$ compared with that at $3 \mathrm{~m} / \mathrm{s}$, and the maximum cutting stress decreased about $20 \%$ from $3 \mathrm{~m} / \mathrm{s}$ to $15 \mathrm{~m} / \mathrm{s}$. (2) Cutting temperature increased from $58{ }^{\circ} \mathrm{C}$ to $112{ }^{\circ} \mathrm{C}$, which increased by $93 \%$. (3) In the process, the cutting force decreased with the higher cutting speed, and the most likely explanation can be deduced: Most chips contacted with the rake face, and with cutting speed increasing, the temperature gradually increased and the material softened, then the workpiece material was easier to remove and the friction between chip and tool decreased. So as cutting continued, the material softening level increased and the cutting force tended to be stable gradually, which was related to cutting temperature, so that the growth rate of temperature decreased and the cutting temperature became stable gradually. (4) After KDP crystal processing, there is tensile stress on the subsurface, which is about $3 \mathrm{MPa} 10 \mathrm{MPa}$. (5) There is also a residual temperature of $30{ }^{\circ} \mathrm{C} \sim 50{ }^{\circ} \mathrm{C}$ on the machined surfaces.

\subsection{Influence of Unformed Chip Thickness}

Figure 9a-c show a stress distribution with unformed chip thicknesses of 297, 429 and $622 \mu \mathrm{m}$, respectively, when cutting speed is $10 \mathrm{~m} / \mathrm{s}$. Similar to the situation shown in Figure 5, the compressive stress is distributed in the chips on the tool rake face and in the material near the shear zone. The maximum compressive stress on the shear plane is $235 \mathrm{MPa}, 240 \mathrm{MPa}$ and $280 \mathrm{MPa}$, respectively, and the maximum compressive stress at an unformed chip thickness of $10 \mu \mathrm{m}$ increases by $20 \%$ compared with that at the unformed chip thickness of $297 \mathrm{~nm}$. 


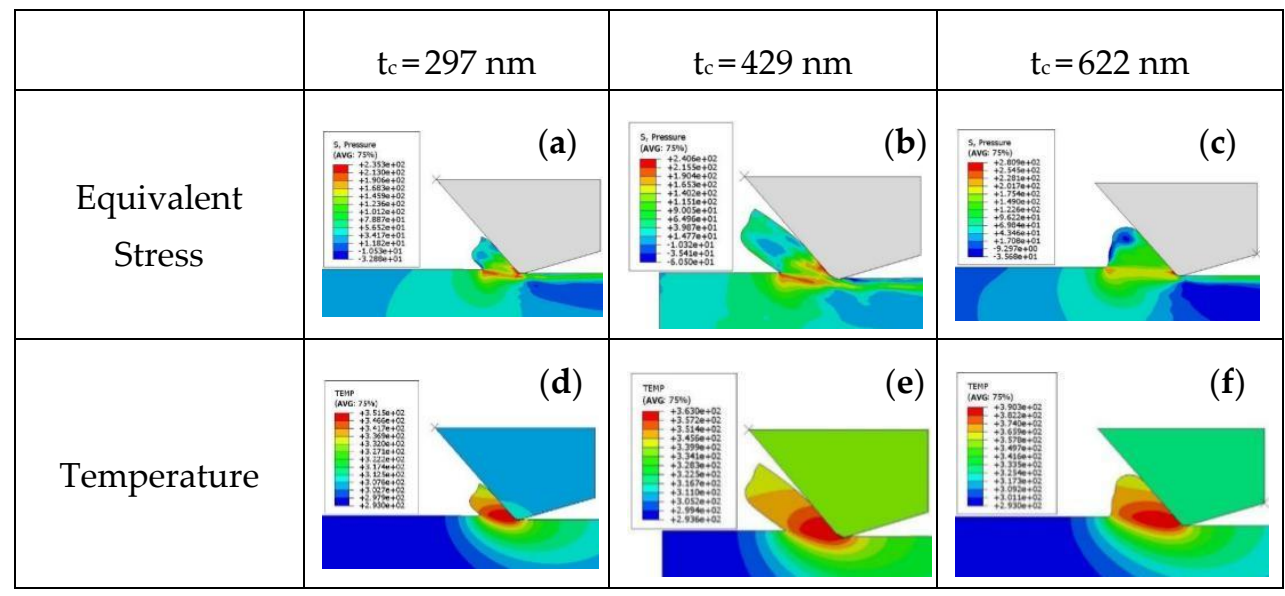

Figure 9. Stress distribution and temperature distribution at different unformed chip thicknesses at cutting speed of $10 \mathrm{~m} / \mathrm{s}$ : (a) Equivalent Stress of tc $=297 \mathrm{~nm}$; (b) Equivalent Stress of tc $=429 \mathrm{~nm}$; (c) Equivalent Stress of tc $=622 \mathrm{~nm}$; (d) Temperature of tc $=297 \mathrm{~nm} ;(\mathbf{e})$ Temperature of tc $=429 \mathrm{~nm} ;(\mathbf{f})$ Temperature of tc $=622 \mathrm{~nm}$.

Figure $9 \mathrm{~d}-\mathrm{f}$ show the KDP crystal temperature distribution with unformed chip thicknesses of $297 \mathrm{~nm}, 429 \mathrm{~nm}$ and $622 \mathrm{~nm}$, respectively, when cutting speed is $10 \mathrm{~m} / \mathrm{s}$. The maximum temperatures of the chips are $76^{\circ} \mathrm{C}, 98^{\circ} \mathrm{C}$, and $117^{\circ} \mathrm{C}$.

In Figure 9, (1) when the cutting speed is $10 \mathrm{~m} / \mathrm{s}$, as the unformed chip thickness increases, the cutting force at $10 \mu \mathrm{m}$ is $140 \%$ higher than that at $297 \mathrm{~nm}$; however, the maximum compressive stress increases by only $20 \%$. (2) The maximum chip temperature increases by $28 \%$ when the unformed chip thickness is $429 \mathrm{~nm}$ compared with $2 \mu \mathrm{m}$, while the maximum chip temperature increases by $19 \%$ when the unformed chip thickness is $622 \mathrm{~nm}$ compared with $429 \mathrm{~nm}$. As the depth of the cut increases, the amount of chips increases, and the amount of chips rubbed against the tool will remain in a relatively stable range to a certain extent, and the frictional heat generation will be stable, so the temperature growth rate will decrease.

\subsection{Chip Morphology}

Figure 10a shows the KDP chip produced by finishing. The max value of the unformed chip thickness is about $297 \mathrm{~nm}$ and the cutting speed is $10 \mathrm{~m} / \mathrm{s}$. It shows the cutting temperature is about $70{ }^{\circ} \mathrm{C}$. It is not difficult to find that the chip is continuous and striplike, and the surface is smooth and complete, so that low temperature has little influence on the KDP crystal structure, and such chip morphology is ideal (Figure 10b,c). 


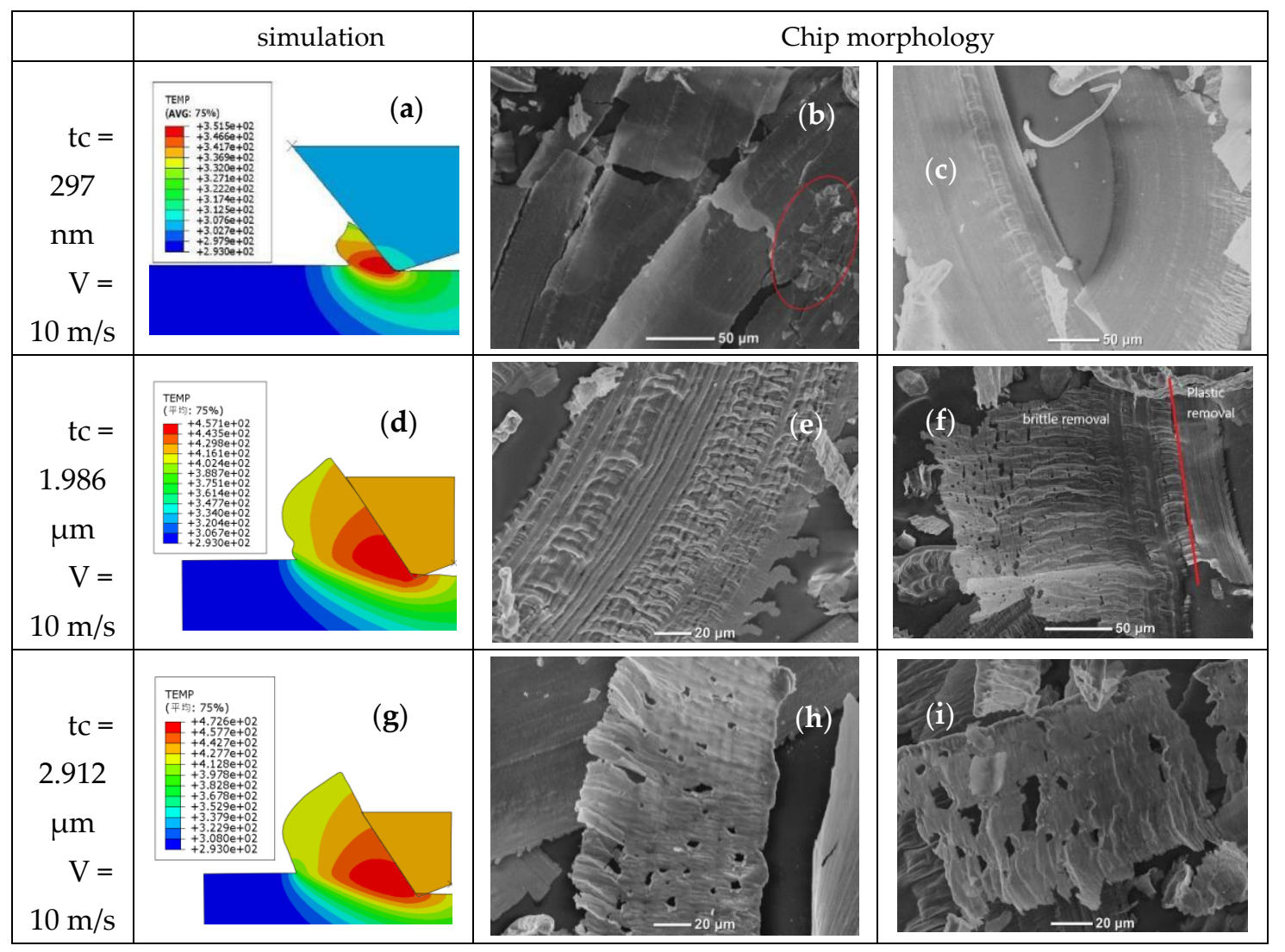

Figure 10. Chip morphology of KDP crystal at different processing stages: (a) Temperature of tc $=297 \mathrm{~nm}, \mathrm{~V}=10 \mathrm{~m} / \mathrm{s}$; $(\mathbf{b}, \mathbf{c})$ Finishing chip morphology; (d) Temperature of tc $=1.986 \mu \mathrm{m}, \mathrm{V}=10 \mathrm{~m} / \mathrm{s} ;(\mathbf{e}, \mathbf{f})$ semi-finished chip morphology; (g) Temperature of tc $=2.912 \mu \mathrm{m}, \mathrm{V}=10 \mathrm{~m} / \mathrm{s}$; (h,i) Roughing chip morphology.

The max value of the unformed chip thickness is about $1.986 \mu \mathrm{m}$. From the simulation results in Figure $10 \mathrm{~d}$, the cutting temperature is $184^{\circ} \mathrm{C}$. In Figure $10 \mathrm{e}$, we can see that the chip is continuous, but the surface is wrinkled, which means the material is softened and can be more easily deformed, and the chips are produced quickly and accumulated obviously, so the softening chips become wrinkled in the discharging process. In Figure 10f, there is an obvious brittle plastic transformation, and the right side of the chip has a completely smooth appearance because the removal mode of this chip is plastic material removal, while on the left side of the chip, the chip exhibits obvious wrinkles and pore-like morphology because the removal mode is brittle material removal. The main reason for this phenomenon is that the actual undeformed cutting thickness can be increased along the arc-edge tool, which is illustrated in Figure 1b. In one process, the thickness of the two sides of the chip is different. The material on the side whose chip thickness is less than the depth of brittle-plastic transition is removed plastically, and the quality of the chip is better, while the material on the side whose chip thickness is greater than the depth of brittle-plastic transition is mainly removed brittly; therefore, the chip morphology is incomplete and the quality is poor.

The max value of the unformed chip thickness is about $2.912 \mu \mathrm{m}$. From the simulation results in Figure $10 \mathrm{~g}$, the cutting temperature is about $199^{\circ} \mathrm{C}$. In Figure $10 \mathrm{~h}, \mathrm{i}$, it can be seen that the chip shows not only a small segment with obvious fractures, but the surface has obvious wrinkles with serious damage, and at the same time, the burrs on the edge of the chip are melted at a high temperature. In the case of high speed and large unformed chip thickness such as rough processing, the chip temperature can be higher than the phase transition temperature, which makes the material easier to deform and phase transition, so the chip is easier to perforate and melt. 


\section{Discussion}

In this paper, the force and heat changes under different working conditions were analyzed by finite element simulation and experimental research, the chips' morphology under actual working conditions was observed, and then the mechanism of chip formation was analyzed. Next, the structure of KDP crystal can be analyzed and discussed through the existing results and simulations.

First of all, in the simulation and experimental results, under the cutting parameters we used in the KDP finishing, the temperature can reach only $140{ }^{\circ} \mathrm{C}$, which is less than the dehydration temperature of KDP crystal (about $182.3^{\circ} \mathrm{C}$ ). However, in the KDP semifinishing and roughing, the unformed chip thickness is $5 \sim 9$ times higher than that in finishing, so the temperature can reach $184^{\circ} \mathrm{C} \sim 199^{\circ} \mathrm{C}$, and KDP crystals are more likely to dehydrate or deform.

Secondly, in the KDP crystal cutting, taking the cutting speed of $15 \mathrm{~m} / \mathrm{s}$ and the max value of the unformed chip thickness of $429 \mathrm{~nm}$ as an example, the chip temperature measurement value reaches $112{ }^{\circ} \mathrm{C}$, and the temperature difference within the crystal easily exceeds $4{ }^{\circ} \mathrm{C}$. In Figure $8 \mathrm{e}$, the max value of the tensile stress is $7.792 \mathrm{MPa}$, which exceeds the tensile strength limit of $6.67 \mathrm{MPa}$. In summary, this shows that the value of tensile stress is likely to be bigger than the tensile strength of KDP crystal under the combined action of the stress produced by crystal removal and the thermal stress of temperature, resulting in micro-cracks on the machined surface and sub-surface.

Thirdly, the phenomenon that chip morphology changes obviously in Figure $10 \mathrm{e}, \mathrm{f}, \mathrm{h}, \mathrm{i}$ is explained as follows: in the cutting process, the cutting force and temperature act together on the KDP crystal, causing material properties such as hardness and specific heat capacity to change. Then, these changes in material properties will affect the cutting force and cutting temperature to achieve a stable state. In this state, the cutting stress is greater than the compressive strength of the material, and high-temperature chips break. At the same time, the local temperature of the chip has exceeded the phase transition temperature of the KDP crystal, and the material will easily generate a dehydration reaction, and even change the structure and morphology. After the chip is separated from the workpiece, the temperature gradually decreases. The residual stress makes the internal stress of the chip and the processed surface extremely unbalanced, likely causing secondary damage. Thus, microcracks may appear on the surface of the workpiece, and the chips will have perforations and edge melting.

\section{Conclusions}

In this paper, the cutting process of KDP crystal is studied by combining finite element simulations, measurement experiments and morphological observation experiments. The main conclusions of this paper are as follows:

1. In this paper, the KDP crystal fly-cutting simulation model is established, the stress field, cutting force and cutting temperature are calculated, and the comparison experiment is carried out to verify the validity of the model. The maximum difference between the simulation temperature and the experimental results is less than $10^{\circ} \mathrm{C}$, which shows that the accuracy of the finite element simulation model can be accepted.

2. The chip morphology of KDP crystal has been observed. Based on the finite element simulation results of the stress field and temperature field, the causes of chip morphology formation and surface cracks of the workpiece have been analyzed.

3. When the max value of the unformed chip thickness is $429 \mathrm{~nm}$, and cutting speed is $15 \mathrm{~m} / \mathrm{s}$, the measured chip temperature reaches approximately $110^{\circ} \mathrm{C}$, and at the time there is also a residual temperature of $30{ }^{\circ} \mathrm{C} \sim 50{ }^{\circ} \mathrm{C}$ on the machined surface and a tensile stress of $7.792 \mathrm{MPa}$, possibly resulting in micro-cracks on the machined surface and sub-surface.

4. In the case of semi-finishing and roughing, the chip temperature can reach $184{ }^{\circ} \mathrm{C}$ or higher, and it is quite possible for the KDP crystal to undergo a phase change reaction in the fly-cutting process, which makes the material easier to deform, and the chip 
is easier to perforate and melt, while higher residual temperatures can more easily damage the machined surface.

Author Contributions: Conceptualization, C.A.; validation, J.Z.; formal analysis, K.F.; investigation, C.A.; writing—original draft preparation, X.Y.; writing—review and editing, H.L.; visualization, X.Y.; supervision, X.L.; project administration, Q.X.; funding acquisition, W.W. All authors have read and agreed to the published version of the manuscript.

Funding: Supported by NSAF U1830110, and Sichuan Province Science \& Technology Project 2020JDRC0010.

Conflicts of Interest: The authors declare no conflict of interest.

\section{References}

1. Guo, D.; Jiang, X.; Huang, J.; Wang, F.; Liu, H.; Zu, X. Effect of UV Laser Conditioning on the Structure of KDP Crystal. Adv. Condens. Matter Phys. 2014, 2014, 238-244. [CrossRef]

2. Chen, M.; Li, M.; Jiang, W.; Xu, Q. Influence of period and amplitude of microwaviness on KH[sub 2]PO[sub 4] crystal's laser damage threshold. J. Appl. Phys. 2010, 108, 43109. [CrossRef]

3. Katagiri, M.; Namba, Y. Optical Surface Generation of KDP Inorganic Nonlinear Optical Crystals by Ultraprecision Surface Grinding. J. Jpn. Soc. Precis. Eng. 1999, 65, 888-892. [CrossRef]

4. Menapace, J.A.; Ehrmann, P.R.; Bickel, R.C. Magnetorheological finishing (MRF) of potassium dihydrogen phosphate (KDP) crystals: Nonaqueous fluids development, optical finish, and laser damage performance at $1064 \mathrm{~nm}$ and $532 \mathrm{~nm}$. Proc. SPIE 2009, 7504, 750414. [CrossRef]

5. Chen, D.; Chen, J.; Wang, B. A hybrid method for crackless and high-efficiency ultraprecision chamfering of KDP crystal. Int. J. Adv. Manuf. Technol. 2016, 87, 293-302. [CrossRef]

6. An, C.; Zhang, Y.; Xu, Q.; Zhang, F.; Zhang, J.; Zhang, L.; Wang, J. Modeling of dynamic characteristic of the aerostatic bearing spindle in an ultra-precision fly cutting machine. Int. J. Mach. Tools Manuf. 2010, 50, 374-385. [CrossRef]

7. Paturi, U.M.R.; Narala, S.K.R. Constitutive flow stress formulation, model validation and FE cutting simulation for AA7075-T6 aluminum alloy. Mater. Sci. Eng. A 2014, 605, 176-185. [CrossRef]

8. Zhou, M.; Zou, L. Tool wear mechanism of diamond cutting of ferrous metals in frictional wear experiments. Opt. Precis. Eng. 2013, 21, 1786-1794. [CrossRef]

9. Ding, J.; Zhao, Y.; Wang, S.; Gu, Y.; Cui, H.; Liu, H.; Xu, G. Investigation on high temperature behavior and thermal dehydration kinetics of KDP Crystal. J. Synth. Cryst. 2015, 44, 235-241. [CrossRef]

10. Lo, S.-P. An analysis of cutting under different rake angles using the finite element method. J. Mater. Process. Technol. 2000, 105, 143-151. [CrossRef]

11. Zong, W.J.; Li, D.; Cheng, K.; Sun, T.; Liang, Y.C. Finite element optimization of diamond tool geometry and cutting-process parameters based on surface residual stresses. Int. J. Adv. Manuf. Technol. 2007, 32, 666-674. [CrossRef]

12. Zong, W.; Sun, T.; Li, D.; Cheng, K.; Liang, Y. FEM optimization of tool geometry based on the machined near surface's residual stresses generate. J. Mater. Process. Technol. 2006, 180, 271-278. [CrossRef]

13. Zong, W.J.; Li, Z.Q.; Zhang, L.; Liang, Y.C.; Sun, T.; An, C.H.; Zhang, J.F.; Zhou, L.; Wang, J. Finite element simulation of diamond tool geometries affecting the 3D surface topography in fly cutting of KDP crystals. Int. J. Adv. Manuf. Technol. 2013, 68, 1927-1936. [CrossRef]

14. Wang, S.; An, C.; Zhang, F.; Wang, J.; Lei, X.; Zhang, J. Simulation research on the anisotropic cutting mechanism of KDP crystal using a new constitutive model. Mach. Sci. Technol. 2017, 21, 202-222. [CrossRef]

15. An, C.; Feng, K.; Wang, W.; Xu, Q.; Lei, X.; Zhang, J.; Wang, S. Study on thermal field in fly-cutting process of DKDP crystal. Int. J. Adv. Manuf. Technol. 2019, 103, 3013-3024. [CrossRef]

16. Zhang, Q.Y.; Liu, D.J.; Wang, S.L.; Zhang, N.; Mu, X.M.; Sun, Y. Mechanical Parameters Test and Analysis for KDP Crystal . J. Synth. Cryst. 2009, 38, 1313-1319.

17. Hou, N.; Zhang, Y.; Zhang, L.; Zhang, F. Assessing microstructure changes in potassium dihydrogen phosphate crystals induced by mechanical stresses. Scr. Mater. 2016, 113, 48-50. [CrossRef]

18. Huang, P.; Wang, S.; Wang, D.; Liu, H.; Liu, G.; Xu, L.; Huang, P. Study on the cracking of a KDP seed crystal caused by temperature nonuniformity. CrystEngComm 2018, 20, 3171-3178. [CrossRef]

19. Barrow, G.A. A review of experimental and theoretical techniques for assessing cutting temperatures. Ann. CIRP Ann. Manuf. Technol. 1973, 22, 203-211.

20. Stephenson, D.; Ali, A. Tool Temperatures in Interrupted Metal Cutting. J. Eng. Ind. 1992, 114, 127-136. [CrossRef]

21. Chen, W.-C.; Tsao, C.-C.; Liang, P.-W. Determination of temperature distributions on the rake face of cutting tools using a remote method. Int. Commun. Heat Mass Transf. 1997, 24, 161-170. [CrossRef]

22. Fang, T.; Lambropoulos, J. Microhardness and Indentation Fracture of Potassium Dihydrogen Phosphate (KDP). J. Am. Ceram. Soc. 2002, 85, 174-178. [CrossRef] 